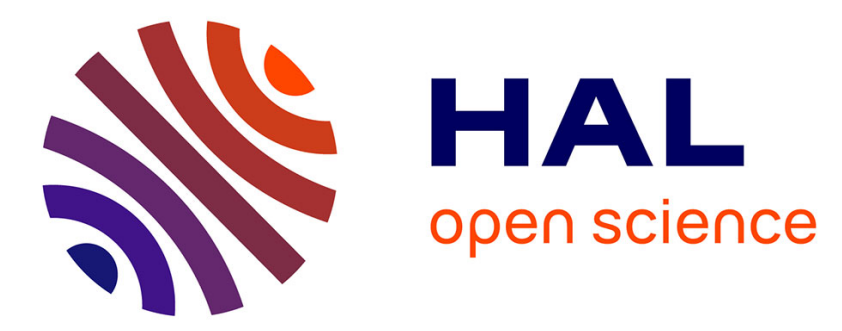

\title{
Differential expression of VGLUT3 in laboratory mouse strains: Impact on drug-induced hyperlocomotion and anxiety-related behaviors
}

Diana y Sakae, Lauriane Ramet, Annabelle Henrion, Odile Poirel, Stéphane Jamain, Salah El Mestikawy, Stéphanie Daumas

\section{To cite this version:}

Diana y Sakae, Lauriane Ramet, Annabelle Henrion, Odile Poirel, Stéphane Jamain, et al.. Differential expression of VGLUT3 in laboratory mouse strains: Impact on drug-induced hyperlocomotion and anxiety-related behaviors. Genes, Brain and Behavior, 2019, 18 (3), pp.e12528. 10.1111/gbb.12528 . hal-02189355

\section{HAL Id: hal-02189355 \\ https://hal.sorbonne-universite.fr/hal-02189355}

Submitted on 19 Jul 2019

HAL is a multi-disciplinary open access archive for the deposit and dissemination of scientific research documents, whether they are published or not. The documents may come from teaching and research institutions in France or abroad, or from public or private research centers.
L'archive ouverte pluridisciplinaire HAL, est destinée au dépôt et à la diffusion de documents scientifiques de niveau recherche, publiés ou non, émanant des établissements d'enseignement et de recherche français ou étrangers, des laboratoires publics ou privés. 


\title{
Differential expression of VGLUT3 in laboratory mouse strains: Impact on drug-induced hyperlocomotion and anxiety-related behaviors
}

\author{
Diana Y. Sakae ${ }^{1}$ | Lauriane Ramet $^{1}$ | Annabelle Henrion ${ }^{2,3,4}$ | Odile Poirel ${ }^{1}$ | \\ Stéphane Jamain ${ }^{2,3,4}$ | Salah El Mestikawy ${ }^{1,5}$ | Stéphanie Daumas ${ }^{1}$ (
}

${ }^{1}$ INSERM, CNRS, Neuroscience Paris SeineInstitut de Biologie Paris Seine (NPS-IBPS),

Sorbonne Université, Paris, France

${ }^{2}$ Inserm U955, Psychiatrie Translationnelle, Créteil, France

${ }^{3}$ Faculté de Médecine, Université Paris Est, Créteil, France

${ }^{4}$ Fondation FondaMental, Créteil, France

${ }^{5}$ Douglas Hospital Research Center, Department of Psychiatry, McGill University, Verdun, Québec, Canada

\section{Correspondence}

Dr Stephanie Daumas, INSERM, CNRS, Neuroscience Paris Seine-Institut de Biologie Paris Seine (NPS-IBPS), Sorbonne Université, 9 quai St Bernard 75005 Paris, France.

Email: stephanie.daumas@sorbonneuniversite.fr

Funding information

Agence Nationale pour la Recherche; Centre National de la Recherche Scientifique;

Fédération pour la Recherche sur le Cerveau; Fondation pour la Recherche Médicale, Grant/ Award Numbers: Equipe FRM

DEQ20130326486, FDT20140930909; Institut National de la Santé et de la Recherche Médicale; Investissements d'Avenir, Grant/ Award Number: ANR-11-IDEX-0004-02 (Labex BioPsy); Natural Sciences and

Engineering Research Council of Canada; Association Sorbonne Université; Ministère de l'enseignement supérieur et de la recherche; École des Neuroscience de Paris (ENP)
The atypical vesicular glutamate transporter VGLUT3 is present in subpopulations of GABAergic interneurons in the cortex and the hippocampus, in subgroups of serotoninergic neurons in raphe nuclei, and in cholinergic interneurons in the striatum. C56BL/6N mice that no longer express VGLUT3 (VGLUT3 ${ }^{-/}$) display anxiety-associated phenotype, increased spontaneous and cocaine-induced locomotor activity and decreased haloperidol-induced catalepsy. Inbred mouse strains differ markedly in their sensitivity to anxiety and behavioral responses elicited by drugs. The purpose of this study was to investigate strain differences in VGLUT3 expression levels and its potential correlates with anxiety and reward-guided behaviors. Five inbred mouse lines were chosen according to their contrasted anxiety and drugs sensitivity: C57BL/6N, $\mathrm{C} 3 \mathrm{H} / \mathrm{HeN}, \mathrm{DBA} / 2 \mathrm{~J}, 129 / \mathrm{Sv}$, and BALB/c. VGLUT3 protein expression was measured in different brain areas involved in reward or mood regulation (such as the striatum, the hippocampus, and raphe nuclei) and genetic variations in S/c17a8, the gene encoding for VGLUT3, have been explored. These five inbred mouse strains express very different levels of VGLUT3, which cannot be attributed to the genetic variation of the SIc17a8 locus. Furthermore, mice behavior in the open field, elevated plus maze, spontaneous- and cocaine-induced locomotor was highly heterogeneous and only partially correlated to VGLUT3 levels. These data highlight the fact that one single gene polymorphism could not account for VGLUT3 expression variations, and that region specific VGLUT3 expression level variations might play a key role in the modulation of discrete behaviors.

\section{KEYWORDS}

129Sv, anxiety, BALB/c, C3H, C57BI6/N, DBA2, locomotion, vesicular glutamate transporter (VGLUT3)

\section{1 | INTRODUCTION}

Glutamate plays a major role in neurotransmission and around $50 \%$ to $70 \%$ of all brain synapses release glutamate. ${ }^{1}$ To act as a neurotransmitter glutamate has to be accumulated inside synaptic vesicles,

Diana Y. Sakae and and Lauriane Ramet contributed equally to this study. allowing its exocytotic release in the synaptic cleft. The transport of cytosolic glutamate into vesicles is operated by Vesicular Glutamate Transporters types 1, 2 and 3 (VGLUT1, -2, -3). ${ }^{2}$ All three VGLUTs have similar functional properties and show almost complementary expression in the brain. VGLUT1 is mainly expressed by cortical areas, and VGLUT2 by subcortical areas. ${ }^{3,4}$ While VGLUT1 and VGLUT2 are present mainly in glutamatergic neurons, VGLUT3 is observed in 
neurons utilizing other neurotransmitters. ${ }^{2}$ For instance, VGLUT3 is expressed by subpopulations of GABAergic interneurons in the cortex and the hippocampus, serotoninergic neurons in the raphe nuclei, and in cholinergic interneurons in the striatum. ${ }^{5,6}$ In these neurons, VGLUT3 allows glutamate to be released as well as potentiate vesicular filling ${ }^{2,7}$ and therefore regulates the amount of release of other neurotransmitters, that is, $\gamma$-aminobutyric acid (GABA), serotonin or acetylcholine. ${ }^{7-10}$ C57BL/6N mice lacking VGLUT3 (VGLUT3 ${ }^{-/-}$mice) display higher anxiety-associated and striatal-related behaviors (such as increased spontaneous hyperactivity and cocaine-induced locomotor activity $[\mathrm{LMA}]^{8,9,11}$ ). The use of knockout mice is a powerful tool to determine the contribution of selected genes in specific and complex behaviors. ${ }^{12-17}$ However, these behaviors also depend on the genetic background of various mouse strains. ${ }^{16,18,19}$ Several studies already showed phenotypic differences between inbred mouse strains for both anxiety and behavioral responses elicited by drugs. ${ }^{20-25}$

The first aim of this study was to assess whether the level of VGLUT3 expression was different in various mouse strains. The second aim was to investigate whether these variations of expression could be related to some VGLUT3-dependent phenotypic traits previously reported in VGLUT3 ${ }^{-/-}$mice. ${ }^{11}$ We measured VGLUT3 protein expression levels in the striatum, hippocampus and raphe nuclei of different mouse strains and correlated them to their anxiety-like and cocaine-induced locomotor behaviors. These brain regions were selected for their known involvement in the regulation of mood or reward behaviors. Five inbred mouse lines commonly used in laboratories were studied (C57BL/6N, C3HeN, DBA/2J and 129/Sv, BALB/ c) and compared with VGLUT3 ${ }^{-1-}$ mice (C57BL/6N background). Substantial differences between strains' behaviors were observed, as well as variations in the level of VGLUT3 expression. However, no direct correlation could be established between the strain-specific genetic variations in SIc17a8, the gene encoding VGLUT3 and VGLUT3 levels. VGLUT3 levels did correlate to some extent with a few behaviors. This finding suggests that glutamatergic cotransmission and VGLUT3-dependent vesicular filling of other neurotransmitters might play a key role in modulating neuronal networks but only in some discrete behavioral aspects.

\section{2 | MATERIALS AND METHODS}

\section{1 | Animals}

BALB/cJ, DBA2/J and C3H/HeN mice were supplied by Janvier Labs (Le Genest St Isle, France), and 129S2/Sv by Charles River (L'Arbresle, France). Male mice were 6 weeks old upon arrival. C57BL/6N and VGLUT3 $^{-/-}$mice (C57BL/6N background) were obtained from our breeding facility. All mice were kept in groups of 4 per cage, housed in a temperature-controlled room $\left(21 \pm 2^{\circ} \mathrm{C}\right)$ with ad libitum access to water and food under a light/dark cycle of 12 hours (light ON from 7:30 AM to 7:30 PM). Three independent groups of mice were used: one for the behavior ( $n=58$ ), one for the anatomy (immunoautoradiography $[I A R])(n=19)$ and one for the genetics $(n=20)$ (see Table 1 for details). Behavioral experiments were performed on 8 to 12 weeks old mice during light phase. All experiments were performed in accordance with the European Union guidelines (directive 2010/63/EU), and with the approval of the French Ministère de l'Agriculture et de la Forêt, Service Vétérinaire de la Santé et de la Protection Animale (authorization \#01482.01 from ethics committee Darwin \#5). All efforts were made to minimize the number of animals used in the course of the study and to ensure their well-being.

\section{2 | Behavioral analysis}

Animals were first tested in the open field (OF), a couple of days later in the elevated plus maze (EPM), and after a week delay in a circular corridor for cocaine-induced LMA. The group size varies from 7 to 10-exact numbers are presented in Table 1. All graphs represent the mean \pm scanning electron microscope (SEM).

\subsection{1 | OF test}

The OF test was performed in a white perplex arena $(43 \times 43 \times 26 \mathrm{~cm})$ located in a 50-Ix illuminated room. The virtual central compartment square represents one third of the total arena. Mice were introduced into the central area and allowed to freely explore the OF for 360 seconds. We recorded duration, frequency and time course of various behaviors (exploration, walk, rear, stretch and groom-data not shown) exhibited by mice in different regions of the OF (central vs periphery zone) using Viewpoint tracking system (Lyon, France).

\subsection{2 | EPM test}

The EPM consists of two white open arms (OAs) and two black-closed arm (CA) $(66 \times 66 \mathrm{~cm}, 50 \mathrm{~cm}$ high) with a central zone named choice area. The luminosity in the central zone is $50 \mathrm{~lx}$. After 1 hour of habituation in the testing room, animals were placed into the choice area of the maze and tested for 360 seconds. The total time spent in each compartment (open vs CAs) and the number of arms entries were recorded using Viewpoint tracking system. The percentage of duration was calculated using arms occupancy: (OA) duration $\times 100 /(O A+C A)$ duration, therefore excluding the time spent in the central zone.

\subsection{3 | Locomotor activity}

LMA was measured in cyclotron. It consists of a circular corridor with four infrared beams placed at $90^{\circ}$ angles (Imetronic, Pessac, France). The device is connected to an electronic interface for data collection. The consecutive interruption of two adjacent infrared beams (ie, mice moving through one fourth of the circular corridor) was recorded and represents the activity of the animal. For cocaine-induced LMA experiment, after an hour habituation to the activity box, mice were

TABLE 1 Animals used in the different aspect of the study

\begin{tabular}{lcccccc}
$n=$ & $\begin{array}{c}\text { BalB/ } \\
\text { c }\end{array}$ & $\begin{array}{c}\text { DBA/ } \\
\text { OF }\end{array}$ & $\begin{array}{c}\text { C57BL/ } \\
6 \mathrm{~N}\end{array}$ & $\begin{array}{c}\text { C3H/ } \\
\mathrm{HeN}\end{array}$ & $\begin{array}{c}129 / \\
\text { Sv }\end{array}$ & VGLUT3 $^{-/-}$ \\
EPM & 10 & 10 & 8 & 9 & 9 & 8 \\
LMA & 10 & 9 & 8 & 10 & 8 & 7 \\
IAR & 10 & 10 & 7 & 10 & 10 & 10 \\
Genetics & 5 & 4 & 5 & 3 & 3 & - \\
\hline
\end{tabular}

Abbreviations: EPM, elevated-plus maze; Immunoautoradiography (IAR, $n=19)$; LMA, locomotor activity induced by cocaine; OF, open field.

Note: Behavior $(n=58)$, Genetics $(n=20)$. 
injected with saline ( $\mathrm{NaCl} 0.9 \%$, ip), and placed back into the cyclotron for another 1 hour. They were then injected with cocaine $(10 \mathrm{mg}$ $\mathrm{kg}^{-1}$, ip), and recorded for an additional 90 minutes. LMA was recorded in 5-minute intervals for 210 minutes. To assess cocaineinduced hyperlocomotion, we normalized the data by subtracting LMA observed in the 30 minutes following saline injection to the LMA observed in the 30 minutes following cocaine injection.

\section{3 | IAR labeling of VGLUT3}

To assess whether VGLUT3 was differently expressed in various mouse lines, we analyzed multiple brain areas by IAR as previously described. ${ }^{8}$ VGLUT3 density measurements were performed in the striatum, the hippocampus and raphe nuclei of wild-type mice from the different genetic backgrounds $(n=4)$ and compared with VGLUT3 $^{-1-}$ mice (C57BL/6N background; $\left.n=4\right)$. After cervical dislocation, brains were dissected and rapidly frozen in isopenthane at $-30^{\circ} \mathrm{C}$. Fourteen-micrometer-thick coronal brains sections were cut at $-20^{\circ} \mathrm{C}$, thaw-mounted on Superfrost Plus slides and stored at $-80^{\circ} \mathrm{C}$ until use. For each mouse, four coronal sections of each brain area per strain were analyzed. Sections were fixed with $4 \%$ paraformaldehyde at room temperature for 15 minutes and washed with phosphate buffered saline (PBS) containing 3\% bovine serum albumin, $1 \%$ goat serum and 1-mM Nal for an hour (named Buffer A). Sections were then incubated overnight at $4^{\circ} \mathrm{C}$ with buffer $\mathrm{A}$ supplemented with VGLUT3 antiserum (1/20000; Synaptic System), wash out and then incubated for 2 hours at room temperature (RT) in buffer $A$ with anti-rabbit $\left[{ }^{125} \mathrm{I}\right]$-lgG (PerkinElmer, Villebon sur Yvette, France). Rinsed sections were then exposed to $\mathrm{X}$-ray films (Biomax MR, Kodak) for 3 days. Standard radioactive microscales were exposed onto each film to ensure that labeling densities were in the linear range. The densitometry measurements were performed with MCID analysis software version 7.0 (Imaging Research Inc., St Catherines, ON, Canada). Background was determined on white matter areas on each section and subtracted from the densitometry measurements. Areas were identified and defined by comparing sections to the Paxinos mouse brain atlas $(2001)^{26}$ : dorsal striatum (DS) and ventral striatum (VS) were analyzed in coronal sections with +1.54 to +1.10 from bregma; dorsal hippocampus $(\mathrm{DH})$ ranging -1.34 to -2.30 from bregma; ventral hippocampus $(\mathrm{VH})$ from -2.80 to -3.16 ; dorsal raphe nuclei (DRN) and median raphe nuclei (MRN) -4.16 to -4.60 from bregma.

\section{4 | Genetic analysis of VGLUT3 promoter}

In order to determine whether variation of VGLUT3 expression levels in different mouse strains resulted from genetic differences, we sequenced 2540 bp spanning the promoter region and exon 1 as well as $4098 \mathrm{bp}$ spanning the last coding exon and the $3^{\prime}$ untranslated region ( $3^{\prime}-$ UTR) of Slc17a8 (the gene encoding for VGLUT3). Five mice per strain were used. Genomic DNA was extracted from mouse tail using DirectPCR lysis reagent (Viagen Biotech Inc., Los Angeles, California) and $0.2 \mathrm{mg} / \mathrm{mL}$ Proteinase $\mathrm{K}$ solution, according to manufacturers' protocol. The promoter region and the exon 1 flanking regions of SIc17a8 (NM_182959.3) were defined as 1770 bp upstream to the transcription start site, 451 bp of the exon 1 and 319 bp downstream to exon 1. The last exon and its flanking region were defined as 809-bp upstream to exon 12, 2638 bp of exon 12, including 2296 bp of $3^{\prime}$-UTR, and 651-bp downstream to the end of transcription. These regions were amplified by polymerase chain reaction (PCR) and sequenced using BigDye Terminator v3.1 cycle sequencing kit (Thermo Fisher Scientific, Carlsbad, California) and run on a 16-Capillary ABI PRISM 3130xl genetic analyzer after purification using the BigDye XTerminator purification kit (Thermo Fisher Scientific). Chromatograms were analyzed using Genalys $2.8 .2 \mathrm{~b}$ software. ${ }^{27}$ All primers used for PCR amplification and sequence analyses are available on request. We used TargetScanMouse $7.1^{28}$ to check whether identified single-nucleotide polymorphism (SNP) may affect a conserved mammalian microRNA (miRNA) regulatory target sites, and $\mathrm{MAPPER}_{2}{ }^{29}$ to study potential changes in binding sites.

\section{5 | Statistics}

Nonparametric Kruskal-Wallis $\mathrm{H}$ test was used to assess strain differences in VGLUT3 content and in behavioral measures. The MannWhitney $U$ test was used to compare VGLUT3 $^{+/+}$and VGLUT3 $^{-/-}$mice data. Repeated measures analysis of variance (ANOVA) was used to calculate differences across time in the cocaine-induced hyperlocomotion experiment. For correlations analyses, Pearson correlation coefficient $R^{2}$ was calculated. All statistical analyses were performed using GraphPad Prism 6 (Graphpad Software Inc., La Jolla, CA, USA) for MacOS $X$. The threshold for statistical significance was set at $5 \%$.

\section{3 | RESULTS}

\section{1 | Behavioral characterization}

\subsubsection{OF and EPM}

In the OF, a strong strain-specific difference in anxiety-associated LMA (Figure 1A,C, kruskal wallis test (KW), $W=26.35 ; 24.04 ; 26.81$, $P<0.0001$ ) and anxiety-like phenotype (Figure 1D, KW, $W=19.5$, $P=0.0006)$ was observed. Of all strains tested, the $C 57 \mathrm{BL} / 6 \mathrm{~N}$ strain was the less anxious (Figure 1D: B6 vs BALB: $P<0.01$; $B 6$ vs $\mathrm{C} 3 \mathrm{H}$ : $P<0.0001)$. In this test, DBA/2 mice were globally more active than 129/Sv, BALB/C and C3H/HeN (Figure 1A-C, $P<0.01$ for all comparisons). $\mathrm{VGLUT3}^{-/-}$mice show a strong reduction of LMA (boxed bar graphs for: (Figure 1A), peripheral LMA: Mann Whitney test (MW) $U$ test, $U=5, P=0.0127$; (Figure $1 B$ ) central LMA: MW $U$ test, $U=0$, $P=0.0007$; (Figure 1C) total LMA: MW $U$ test, $U=5, P=0.0295$ ), as well as a fivefold higher center occupancy (boxed bar graph Figure 1D, MW $U$ test, $U=0, P=0.0007$ ).

In the EPM test, strain-specific differences were observed in the time spent in OAs (Figure 2A, KW, $W=13.33, P=0.0098$ ), CAs (Figure $2 \mathrm{~B}, \mathrm{KW}, \mathrm{W}=22.95, P<0.0001$ ), percentage of time spent in OAs (Figure $2 \mathrm{E}, \mathrm{KW}, W=10.9, P=0.027$ ), and in the frequency of OAs (Figure 2C, KW, $W=11.36, P=0.0228$ ). However, no differences in CA entries were observed between the five strains (Figure 2D, KW, $W=6.44, P=0.1686$ ). Regarding the OAs analyses (Figure 2A,C,E), statistical differences can be explained by the overall higher exploration rate of the $\mathrm{C} 57 \mathrm{BL} / 6 \mathrm{~N}$ strain. We observed that $129 / \mathrm{Sv}$ also present a significantly lower exploration of the 
(A)

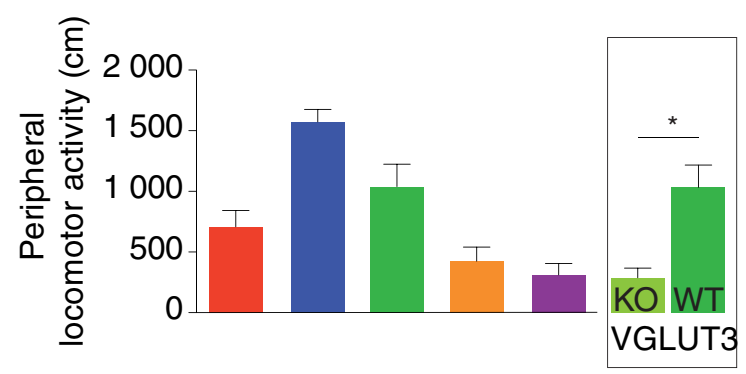

(C)

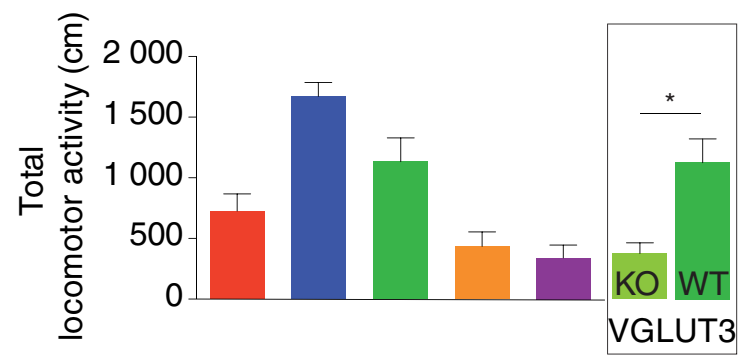

(B)

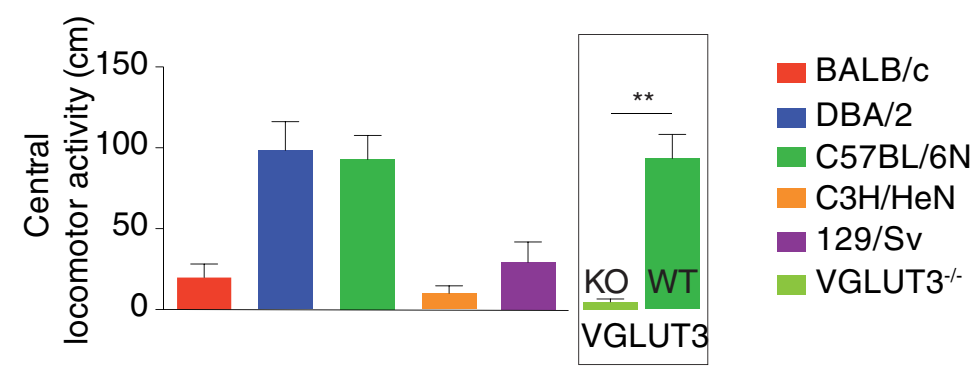

(D)

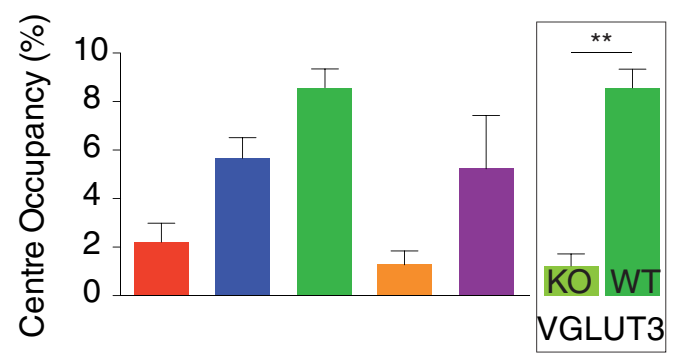

FIGURE 1 Strain effects on LMA and anxiety-related behaviors assessed in the OF test. LMA is represented by (A) the distance run in the peripheral zone, (B) central zone, and (C) the whole OF. (D) The percentage of central occupation illustrated the anxiety level of the animals. For each parameter, VGLUT3 ${ }^{-/}$data are compared with control littermate' in the boxed bar graphs. $* P<0.05$, **P $<0.01$. KO, GLUT3 knock-out; WT, VGLUT3 wild type

(A)

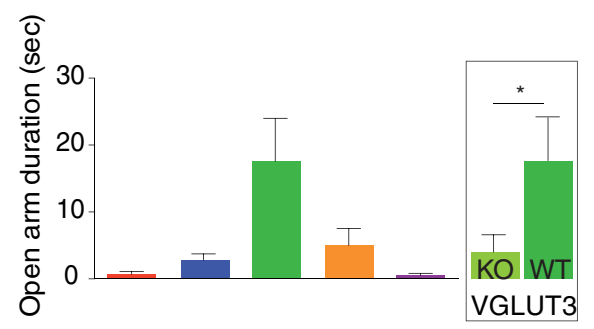

(B)

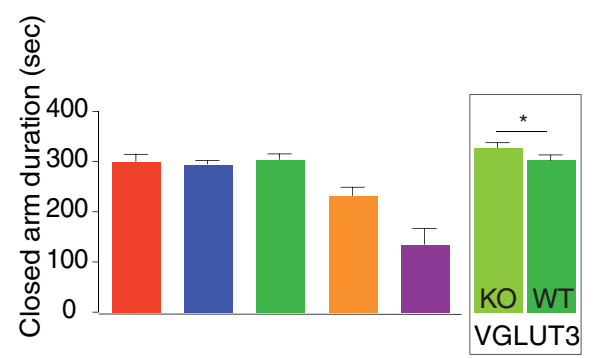

(C)

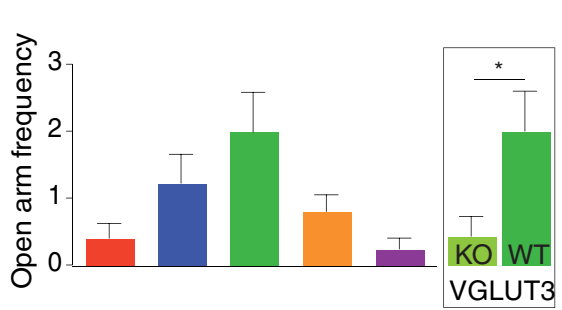

(D)

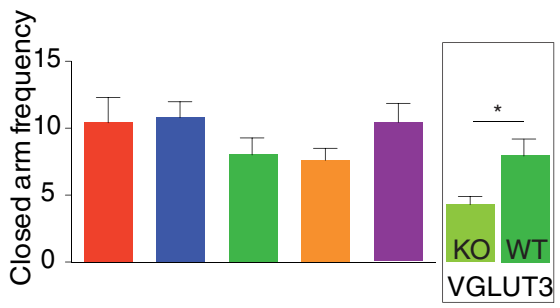

(E)

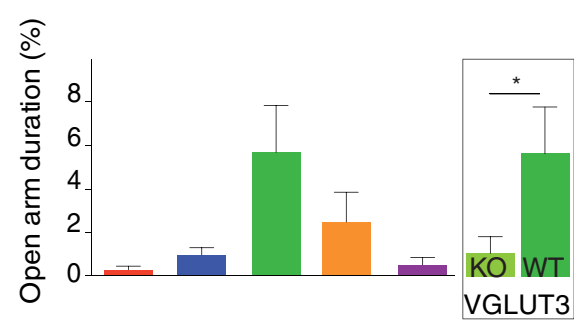

FIGURE 2 Anxiety levels assessed in the five mouse lines and VGLUT3 knock-out mice with the EPM test. The time spent (seconds) in (A) the OAs and (B) CAs is represented in seconds for the different strains and the VGLUT3 ${ }^{-/-}$. The number of entries in: (C) OAs and (D) CAs. (E) Percentage of time spent in the OAs. VGLUT3 ${ }^{-/-}$data are compared with control littermate in the boxed bar graphs. *P < 0.05. KO, VGLUT3 knock-out; WT, VGLUT3 wild type

CAs than $\mathrm{BALB} / \mathrm{C}, \mathrm{DBA} / 2$, and $\mathrm{C} 57 \mathrm{BL} / 6 \mathrm{~N}$ mice (Figure $2 \mathrm{~B}$; $P<0.01$ ). As we previously published, ${ }^{9}$ VGLUT3 $^{-/-}$mice displayed an anxiogenic-like phenotype. In the EPM, they visited less often (Figure $2 \mathrm{C}$ boxed bar graph, $\mathrm{MW} U$ test, $U=10, P=0.0264$ ) and spent less time in the OAs than control littermates (boxed bar graph: Figure 2A, MW $U$ test, $U=8.5, P=0.0183$; Figure $2 \mathrm{E}, \mathrm{MW} U$ test,
$U=8.5, P=0.02$ ). VGLUT3 deletion impacts time spent and the number of visits in the CAs (respectively, boxed bar graph in: Figure 2B, MW $U$ test, $U=11, P=0.0485$; Figure $2 D, M W U$ test, $U=7, P=0.0115)$. VGLUT3 $^{-/-}$mice spent more time in the CAs but show fewer entries, indicating a reduction in LMA in an anxiogenic environment. 
$(\mathrm{A})$

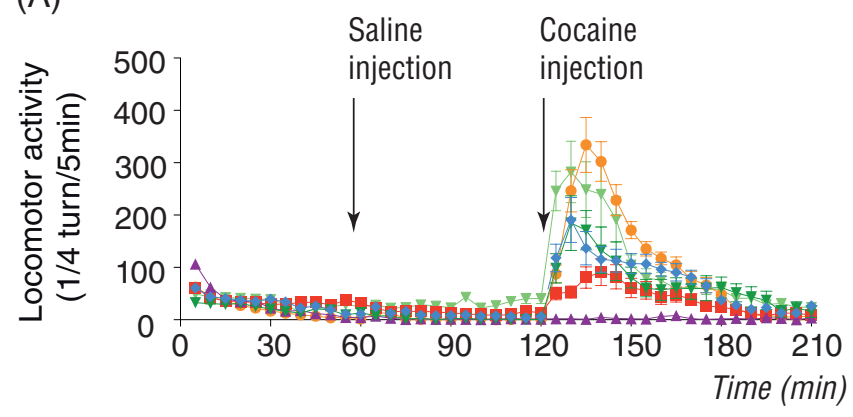

(B)

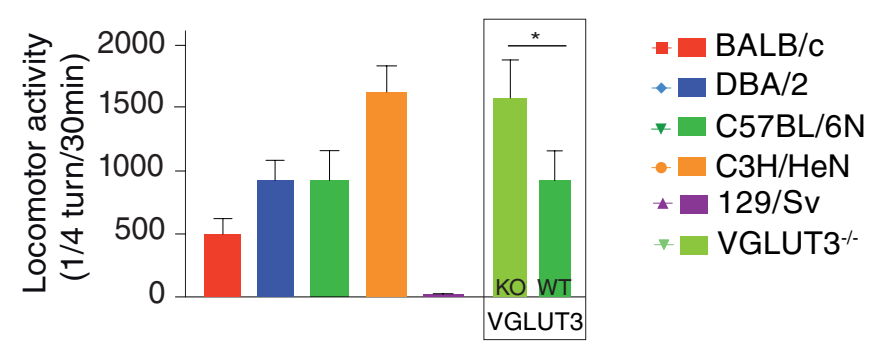

FIGURE 3 Cocaine-induced locomotion in five mouse lines and VGLUT3 knock-out mice. (A) Time course of locomotor activity (LMA) over a 3-hour 30-minute period for the different strains studied. Ip Injection of saline ( $\mathrm{NaCl} 0.9 \%)$ and cocaine (10 mg/ $\mathrm{kg}$ ) are represented on the time line. (B) LMA represented by the one-fourth turn per 30 minutes the animals made after cocaine injection, minus 30 minutes after saline injection. VGLUT3 $^{-/-}$data are compared with control littermate in the boxed bar graph. $* P<0.05$. KO, VGLUT3 knock-out; WT, VGLUT3 wild type

\subsection{2 | Cocaine-induced LMA}

None of the strains reacted to saline injection (Figure $3 \mathrm{~A}$ at 60 minutes). In contrast, all strains except 129/Sv mice showed a hyperlocomotion after cocaine injection (Figure $3 \mathrm{~A}$ see at 120 minutes; 2-way repeated mesures ANOVA (RM-2) ways ANOVA, all $P<0.0001: F_{41,1722}=69.97$ for time, $F_{4,42}=9.456$ for strains, and $F_{42,1722}=11.37$ for time $\times$ strains interaction). The highest LMA was observed for $\mathrm{C} 3 \mathrm{H} / \mathrm{HeN}$ mice, whereas the lowest was observed in $\mathrm{BALB} / \mathrm{c}$, - not including 129/Sv (Figure 3B; KW, $W=31.72$, $P<0.0001)$. Knock-out mice for VGLUT3 express a twofold increase in cocaine-induced LMA compared with control littermates (C57BL/6N), reaching the level of $\mathrm{C} 3 \mathrm{H} / \mathrm{HeN}$ animals (Figure 3B boxed bar graph: $M W$ test, $U=13, P=0.033$ ).

\section{2 | VGLUT3 expression}

As expected, VGLUT3 was not detectable in the whole brain of the VGLUT3 $^{-1-}$ mice $^{8}$ (data not presented). In the DS and VS, VGLUT3 expression fluctuates between strains (KW-test, Figure 4A: DS, $W=15.28, P=0.0042$, Figure 4B: VS, $W=12.83, P=0.0121)$, with levels around 2 times higher in $129 \mathrm{~Sv}, \mathrm{C} 3 \mathrm{HeN}$ and $\mathrm{C} 57 \mathrm{BL} / 6 \mathrm{~N}$ than $\mathrm{BALB} / \mathrm{c}$ and DBA/2 mice. In the hippocampus, VGLUT3 expression gradually decreases from high expression in 129/Sv > C3H/HeN> C57BL/6N to lower expression in DBA/2 > BALB/c (KW test, Figure 4C: $D H, W=13.18, P=0.0104$, and Figure 4D: $V H, W=8.3$, $P=0.0505)$. In raphe nuclei, no differences of VGLUT3 expression were found between strains ( $K W$ test, Figure 4E: DRN, $W=7.46$, $P=0.0874$, and Figure 4F: $M R N, W=7.45, P=0.0879$ ).

Overall, in comparison to $\mathrm{C} 57 \mathrm{BL} / 6 \mathrm{~N}$ mice (set up as the reference $100 \%$; see supplementary data, Figure S1), $129 \mathrm{~Sv}$ and $\mathrm{C} 3 \mathrm{HeN}$ strains had higher VGLUT3 expression levels (respectively $126.9 \pm 9.4 \%$ and $116.4 \pm 3.4 \%, P<0.021$ ), while BALB/c and DBA/2 mice displayed lower VGLUT3 levels (respectively $63.9 \pm 3.7 \%$ and $80.8 \pm 5.7 \%, P<0.035$ ).

\subsection{SLC17A8 regulation regions}

We identified 51 SNPs in the promoter region, and 40 SNPs and 4 indels in the $3^{\prime}$-UTR (Supporting Information Table S1). Most of these SNPs were in linkage disequilibrium $\left(r^{2}=1\right)$ and we thus reduced to seven haplotype-tagging SNPs (ht-SNPs) to specifically define each mouse strain (Figure 5A and Supporting Information Table S1). Only one SNP (rs29353268) in the last exon might explains the overall lower VGLUT3 expression observed both in DBA2 and $B A L B / c$ (see Figure S1).

As the lowest expression observed was in BALB/c mice, we checked which SNPs were shared by C57BL/6N, C3HeN and $129 \mathrm{sv}$, but BALB/c. Hap4 matched these criteria (Supporting Information Table S1). This haplotype spanned two SNPs in the promoter region (rs46766687 and rs29349498) and two SNPs in the last exon (rs29325887 and rs29367655). In the promoter region, only rs29349498 was conserved through evolution. Interestingly, we found this SNP was predicted to change putative binding sites for the AhR and Pax- 8 transcription factors (Figure 5B). However, for both the $G$ allele observed in BALB/c should allow transcription factor binding and thus could not explain the lower expression observed for VGLUT3. Downstream, only rs29367655 was highly conserved through evolution, but no putative miRNA binding site was found to be affected by this SNP (not shown).

\subsection{VGLUT3 expression and behavior characterization: Correlation}

In order to assess the possible link between VGLUT3 protein levels and phenotypic traits, we ran correlation analyses for each parameter.

We first studied the anxiety trait. The only parameter showing correlation with VGLUT3 expression was the time spent in CAs in the EPM. We found a negative correlation between these parameters both in DRN and MRN (Figure 6E,F).

We then performed correlative analysis between the cocaineinduced LMA and VGLUT3 expression in the various brain regions studied (Figure 7). The $129 / \mathrm{Sv}$ line that did not respond to cocaine injection was excluded from this analysis. We found no correlation in the DS or the VS (Figure 7A,B). In contrast, we observed a weak correlation between VGLUT3 densities and LMA in the VH (Figure 7D) and the DRN (Figure 7E).

\section{4 | DISCUSSION}

The application of animal models of anxiety and drug-responses for experimentation in mice is becoming increasingly important for 


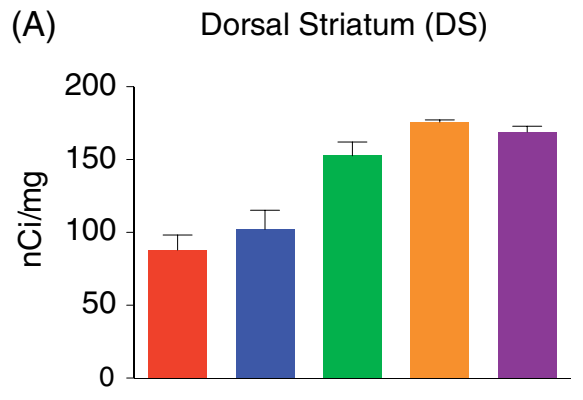

(B) Ventral Striatum (VS)

(C) Dorsal hippocampus (DH)
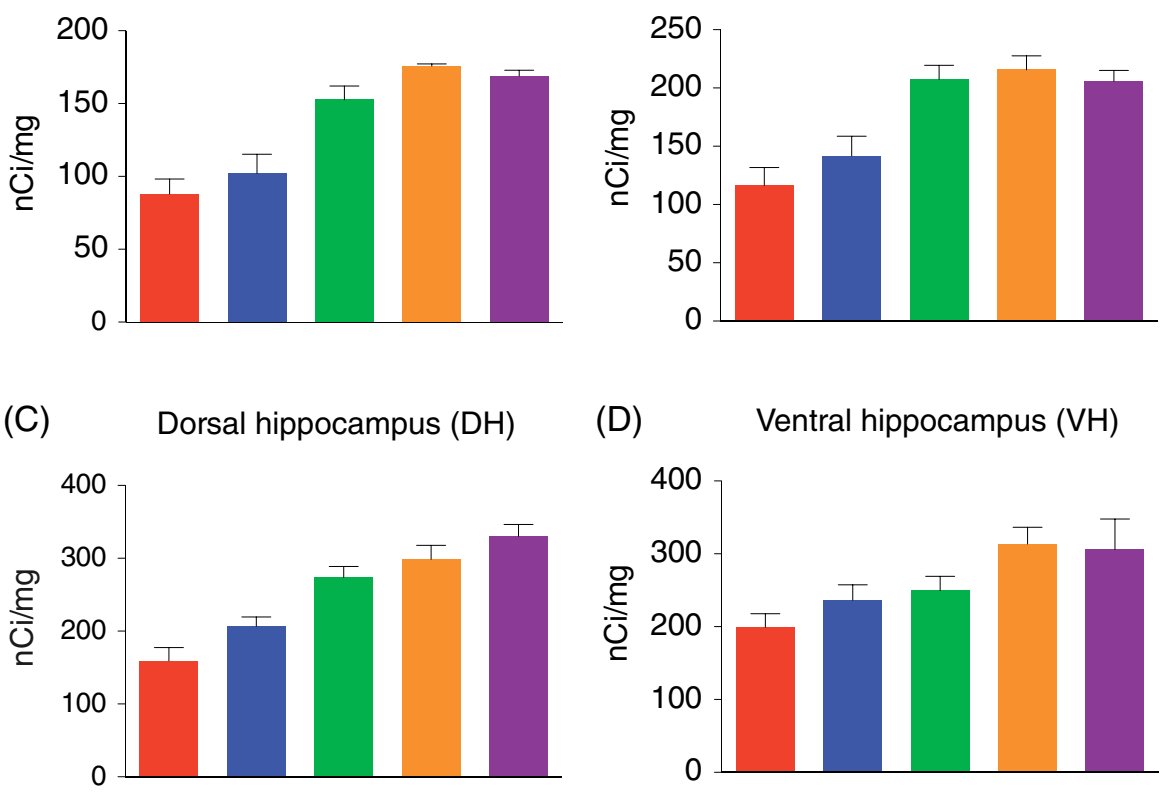

(D) Ventral hippocampus (VH)

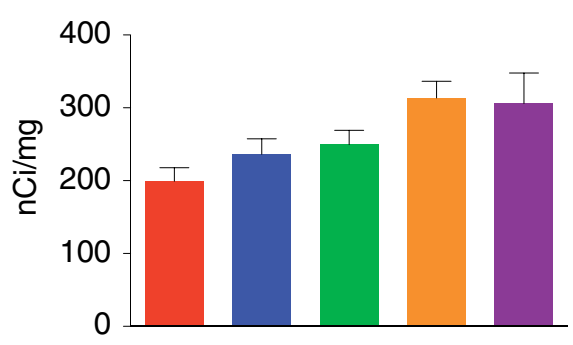

(E) Dorsal raphe nuclei (DRN)

(F) Median raphe nuclei (MRN)
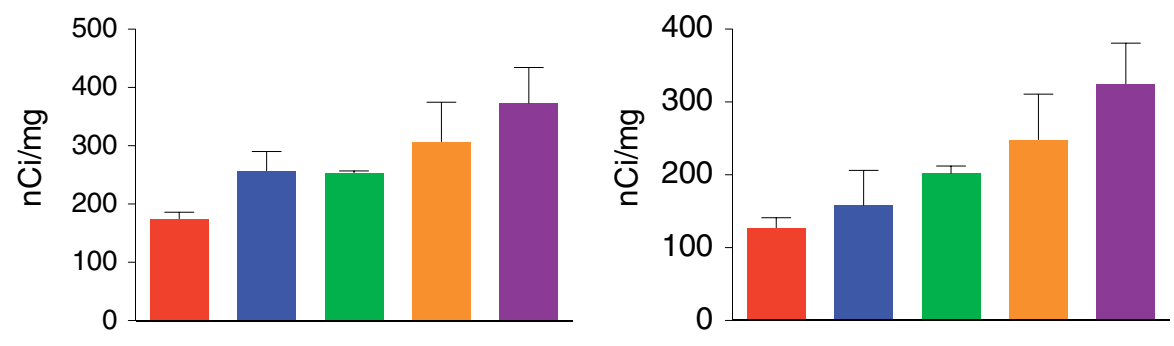

(G) BALB/c DBA/2 C57BL6 C3H/H 129/Sv

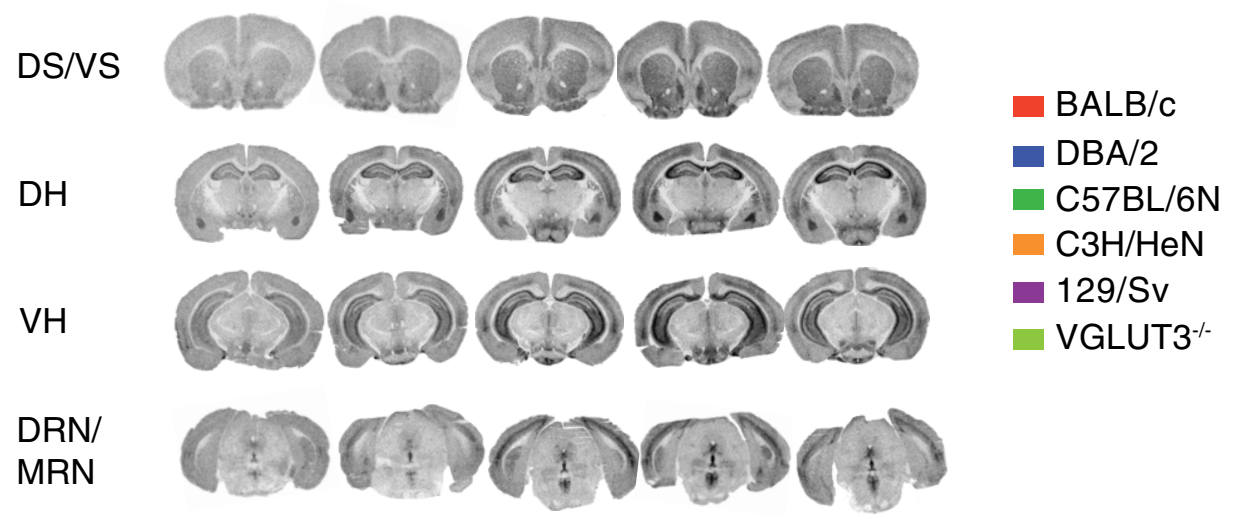

FIGURE 4 Quantification of VGLUT3 content in different brain structures of five mouse lines: (A) DS, (B) VS, (C) DH, (D) VH, (E) DRN, (F) MRN. (G) Representative immunoautoradiographies

studying the contribution of genetic differences, as well as the roles of selected genes, in specific behaviors. By running these experiments, we wanted to better understand ${ }^{1}$ the contribution of genetic differences, as well $\mathrm{as}^{2}$ the contribution of the VGLUT3 gene in specific behaviors of anxiety and addiction.

In previous studies, VGLUT3 ${ }^{-1-}$ mice were used to assess VGLUT3 involvement in the regulation of anxiety and addiction. The absence of VGLUT3 leads to severe changes in anxiety- and addictive-like phenotypes, including cocaine-induced locomotor hyperactivity. ${ }^{9,11}$ To further investigate the association between VGLUT3 and anxiety- or addictive-like behaviors, we herein tested whether variation of VGLUT3 endogenous expression in different mouse strains might be correlated with differences in their anxiety- or addictive-like behaviors. 
(A)

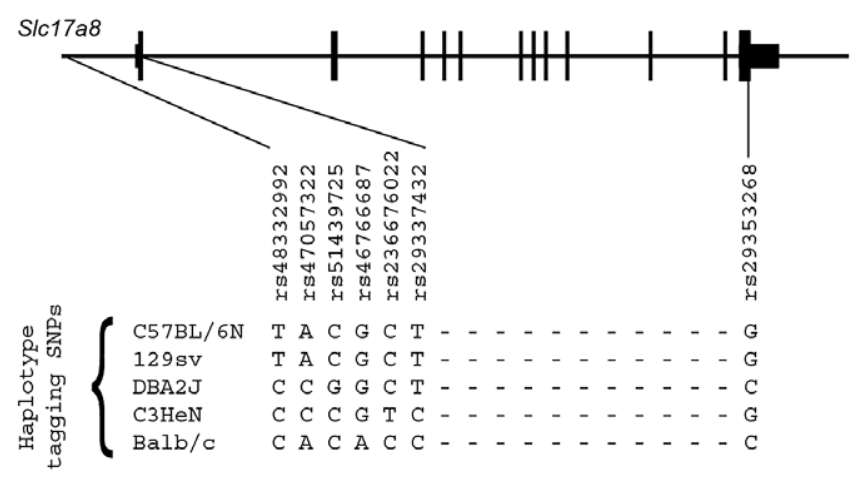

(B)

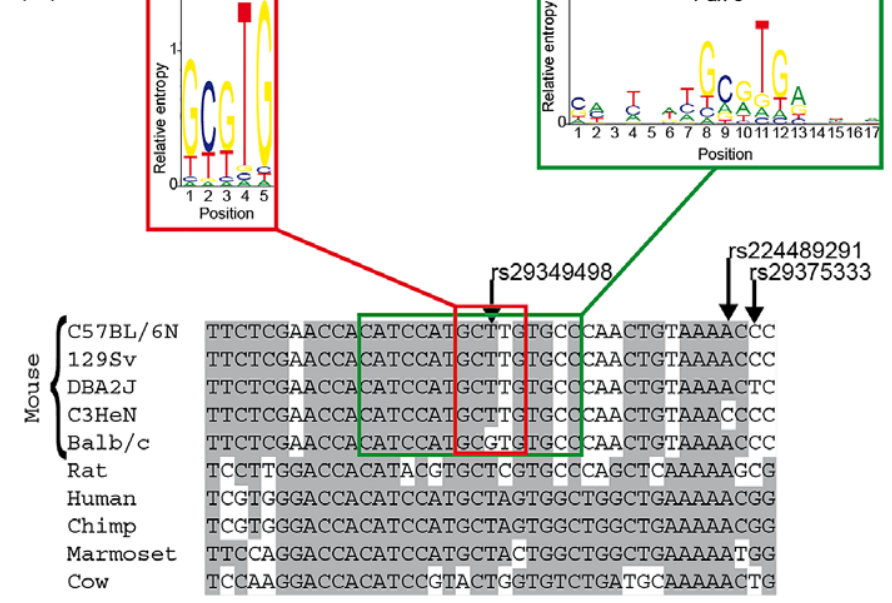

FIGURE 5 Slc17a8 sequence: (A) gene structure of SIc17a8. The coding exons are shown with thick blocks, whereas the thinner represents UTRs. Six haplotype-tagging SNPs have been identified in the promoter region and one in the $3^{\prime}$-UTR defining specific haplotypes for each mouse strain. (B) Genomic alignment of rs29349498. This SNP is located 341-bp upstream to the transcription start site and affects a highly conserved nucleotide. This variation is observed only in BALB/c mice as compared with other mouse strains and alters putative binding site of AhR and Pax-8
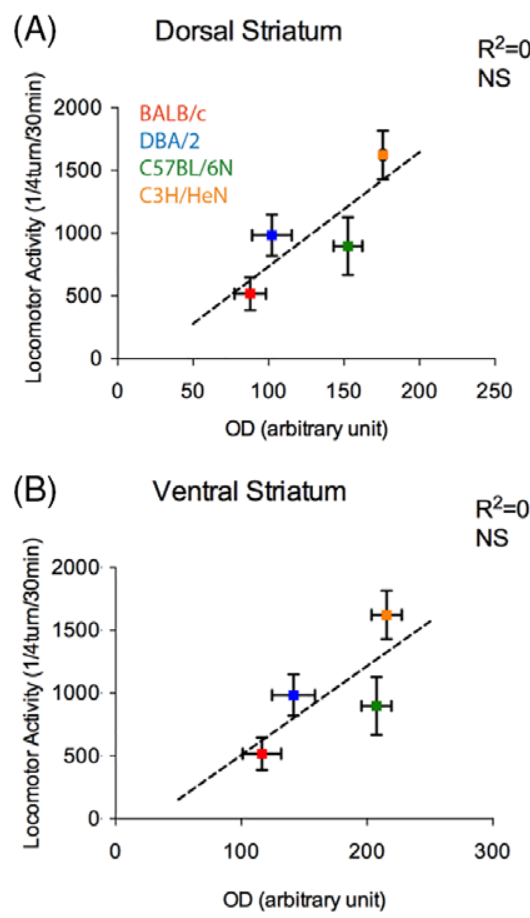

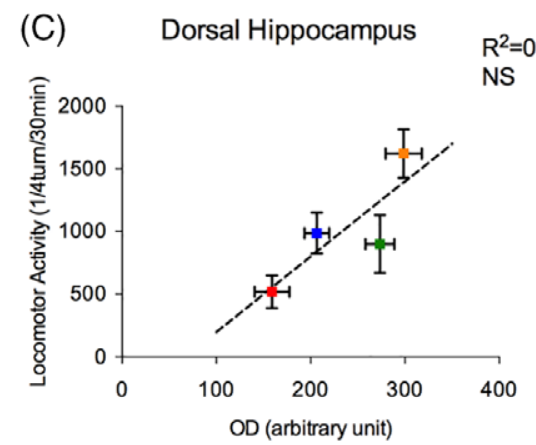

(D)

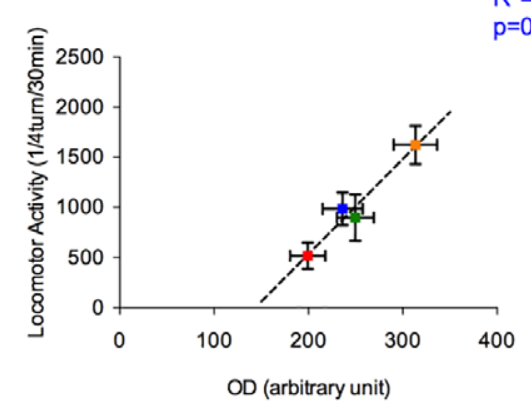

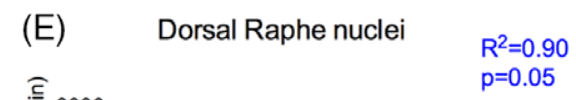
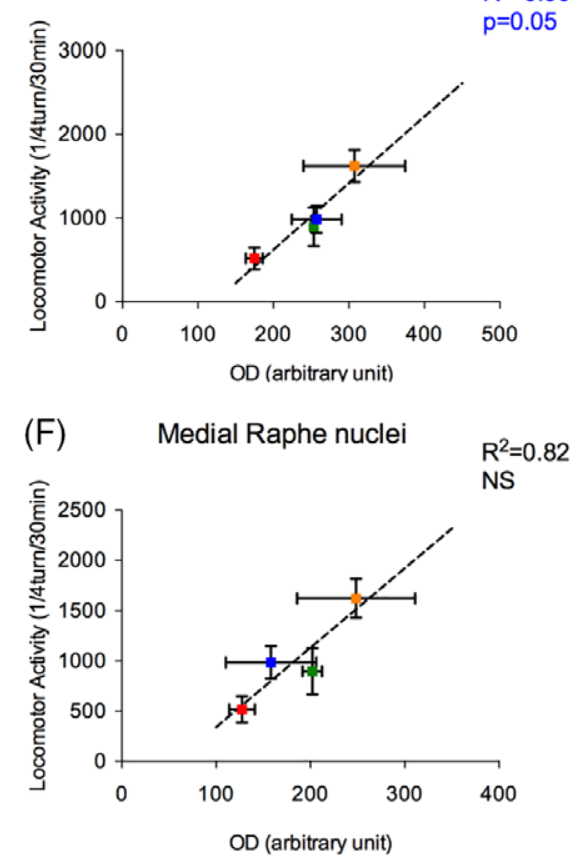

FIGURE 6 Correlation between VGLUT3 expression level in various brain regions and LMA after cocaine injection (excluding 129/Sv strain). Dots represent mean \pm SEM. Pearson correlation coefficients $R^{2}$ are indicated, with $P$ value when significant. (A) DS. (B) VS. (C) DH. (D) VH. (E) DRN. (F) MRN. NS, non significant; OD, optical density

Surprisingly, in our hands, the $129 / \mathrm{Sv}$ mouse strain did not respond to cocaine at $10 \mathrm{mg} / \mathrm{kg}$. Published work showed controversial results concerning $129 / \mathrm{Sv}$ strains. ${ }^{23,30-34}$ It seems that it is not only dependent on the study (ie, behavioral design, provider and drug concentration), but also on the substrain used (129S1/Sv, 129S6/Sv, and 129X1/Sv). For instance, Miner (1997) was the first to describe locomotor activation by cocaine in the $129 \mathrm{~S} 1 / \mathrm{Sv}$ line. ${ }^{31}$ However, the observed increased locomotion due to cocaine injection was not that clear when compared with locomotor activation after saline injection. Crabbe et $\mathrm{al}^{31}$ also found highly variable behaviors in $129 / \mathrm{Sv}$ substrains between labs following cocaine injections. ${ }^{30}$ In our study, we used the $129 \mathrm{~S} 2 / \mathrm{Sv}$ line with a dose of $10 \mathrm{mg} / \mathrm{kg}$ that did not elicit locomotor hyperactivity. This lack of increased-LMA also found in various mutant mice targeting the dopamine receptor or transporter (D1 or dopamine transporter (DAT)) is often consistent with the absence of reinforcing effect of cocaine. ${ }^{35-38}$ Moreover, the $129 /$ Sv line, as the $\mathrm{C} 3 \mathrm{H}$, is known to be especially hypoactive. However, in our hands, $\mathrm{C} 3 \mathrm{H}$ mice showed the highest reaction to cocaine injection, reaching the level of $\mathrm{VGLUT3}^{-/-}$mice. Our results, in agreement with a previous study, ${ }^{34}$ identify C57BL6 and $\mathrm{C} 3 \mathrm{H}$ mice 
(A)

Dorsal striatum

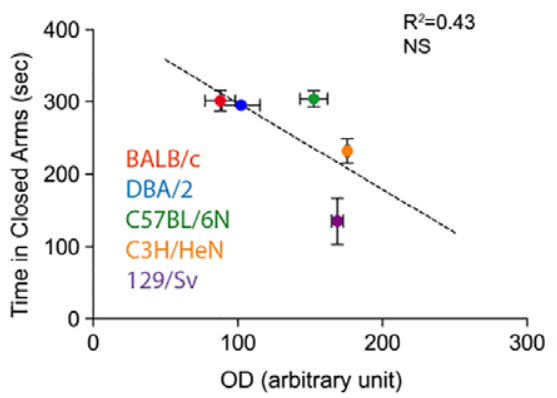

(B) Ventral striatum

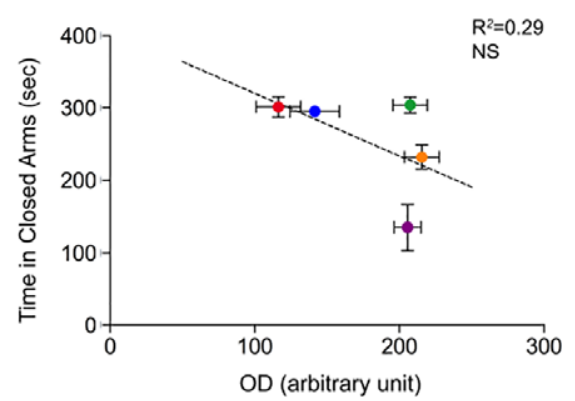

(C) Dorsal hippocampus

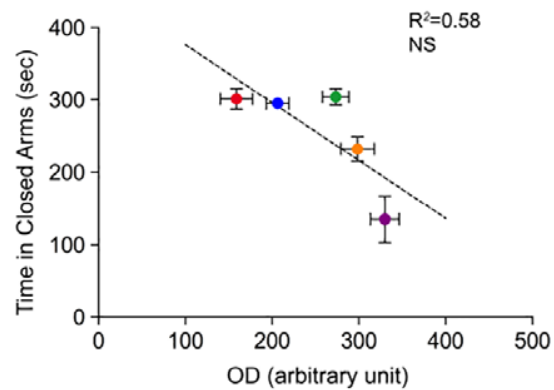

(D) Ventral hippocampus

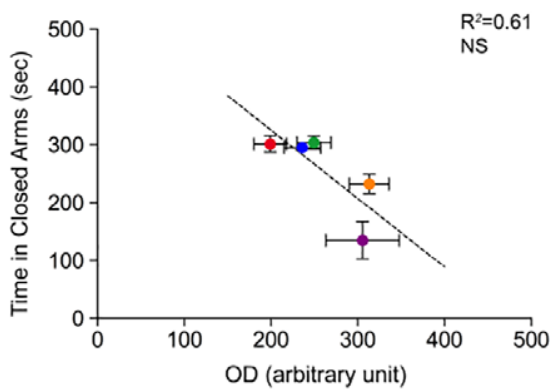

(E) Dorsal Raphe nuclei

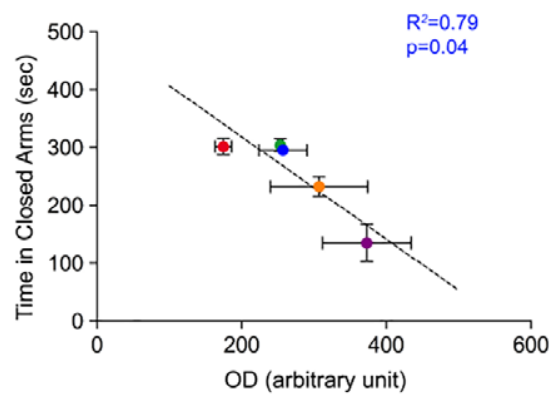

(F) Median Raphe nuclei

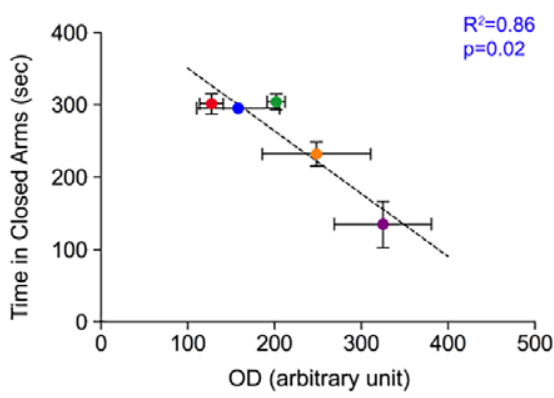

FIGURE 7 Correlation between VGLUT3 expression level in various brain regions and the time spent in CAs in the EPM test. Dots represent mean \pm SEM. Pearson correlation coefficients $R^{2}$ are indicated, with $P$ value when significant. (A) DS. (B) VS. (C) DH. (D) VH. (E) DRN. (F) MRN. NS, non significant; OD, optical density

as the most appropriate lines to study behavioral responses to cocaine.

Consistent with Keum et $\mathrm{al}^{39}$, we found that $\mathrm{C} 3 \mathrm{H} / \mathrm{He}$ mice are low performers and very anxious, especially in the OF test (Figure $1 \mathrm{C}$, D). ${ }^{40}$ They spent less than $2 \%$ in the central zone of the OF whereas B6 mice were the less anxious spending more than $8 \%$ of their time exploring the center. In our hands, DBA/2 and 129/Sv mice display a moderate anxiety-like phenotype, with BALB/c being more anxious, as found by Lad et al. ${ }^{41}$ These discrepancies with published studies can be explained by substrain differences because we used 129S2/Sv instead of $129 \mathrm{~S} 1$ and S4 as in. ${ }^{41,42}$ It could also be due to the fact that mice spent considerable time in the central compartment, a behavior that can be associated with high anxiety levels, because mice can express freezing behavior in the central zone.

In anxiety tests, the illumination intensity is known to be a prime parameter. However, we established the same ranking in anxiety response as previous work despite very different conditions of illumination. ${ }^{39}$ They used a very high intensity (300-330 Ix), compare with our lower measures (50 Ix) supposedly less aversive for the mice. The ranking of the various mouse strains we obtained in EPM and $\mathrm{OF}$ is consistent. Indeed, in both cases, we observed the strongest and the weakest state of anxiety for the BALB/c and B6 strains, respectively, while the DBA/2 and the 129/Sv strains express a moderate anxiety. The $\mathrm{C} 3 \mathrm{H}$ line is the only line for which we noticed discrepancies in the level of expressed anxiety in the EPM and OF test. We observed high anxiety level of $\mathrm{C} 3 \mathrm{H}$ mice in the OF (spending less than $2 \%$ in the central zone), However, in the EPM, they explored more often the OAs, which can be interpreted as a sign of low anxiety.
As we previously highlighted, the $\mathrm{C} 3 \mathrm{H}$ strain is hypoactive. This is also the only known strain used with visual impairments. Both these traits could undoubtedly have a noticeable impact on the EPM exploration. ${ }^{41} \mathrm{~A}$ possible explanation for the difference in anxiety levels observed for this strain between the OF and the EPM is that LMA is recruited differently, with the exploratory activity component priming in the EPM.

In mice, there is an inverse correlation between anxiety levels and LMAs, that is clearly observed in VGLUT3 $^{-/-}$mice. In fact, $\mathrm{VGLUT3}^{-/-}$mice that are hyperactive when placed in normal housing conditions, turn out to be hypoactive when exposed to stressful environments. ${ }^{9,43,44}$

Within each strain, VGLUT3 expression varies substantially according to the brain region involved in anxiety- and drug-related behavior. Between strains, the overall VGLUT3 expression is also different, with $\mathrm{C} 3 \mathrm{H} / \mathrm{HeH}=129 / \mathrm{Sv}, \mathrm{C} 57 \mathrm{BI} / 6 \mathrm{~N}$ and $\mathrm{BALB} / \mathrm{c}=\mathrm{DBA} / 2$, from the highest VGLUT3 expression to the lowest, respectively. More precisely, the striatum (dorsal and ventral) is the brain region showing the highest variability in VGLUT3 expression between the mouse lines. In this area, C57BL/6N mice express the same level of VGLUT3 than $\mathrm{C} 3 \mathrm{H} / \mathrm{HeH}$ and $129 / \mathrm{Sv}$ strains.

Interestingly, the analysis of the Slc17a8 locus identified SNPs associated with the low expression group including BALB/c and DBA/2 strains. However, the relationships between these sequence variations and their impact on the level of VGLUT3 expression has to be elucidated.

We observed high heterogeneity of VGLUT3 expression depending on mice strain that might be partially explained by a SNP in the $\mathrm{BALB} / \mathrm{c}$ and DBA/2 strains. This nucleotide change does not alter the amino acid sequence of the protein and is highly conserved through 
mammalian evolution (not shown), but no known putative miRNA binding site has been described in this region.

Nevertheless, no clear correlation could be established between VGLUT3 expression and behavioral traits, highlighting the fact that even if the ablation of this gene in VGLUT3 ${ }^{-1-}$ mice lead to a clear cut phenotypic pattern (ie, cocaine-induced hyperlocomotion, anxiety-like phenotype), one single gene polymorphism could not be taken responsible for the intrinsic variability observed in various mice line. However, the correlation analysis showed that VGLUT3 could play an important role in two regions regarding LMA and anxiety traits: raphe nuclei and hippocampus. Because VGLUT3 is present in serotoninergic neurons of raphe nuclei and in GABAergic interneurons of the hippocampus $^{7,9}$ the use of mice with a floxed VGLUT3 will enable the spatio-temporal control of VGLUT3 deletion. This method will open the way to a more precise dissection of the contribution of VGLUT3 within specific neuronal populations and behaviors. Finally, this work confirms that the $\mathrm{C} 57 \mathrm{BL} / 6 \mathrm{~N}$ background was the more appropriate to study the behavioral effect of VGLUT3 deletion and illustrates how critical is the choice of the genetic background when engineering new mice models.

\section{ACKNOWLEDGMENTS}

This work was supported by grants from Fondation pour la Recherche Médicale (Équipe FRM DEQ20130326486), Fédération pour la Recherche sur le Cerveau (FRC), Agence Nationale pour la Recherche (ANR), the Fédération pour la Recherche sur le Cerveau (FRC), the Investissements d'Avenir program managed by the ANR under reference ANR-11-IDEX-0004-02 (Labex BioPsy), Institut National de la Santé et de la Recherche Médicale (Inserm), CNRS, and Sorbonne University (SU), Natural Sciences and Engineering Research Council of Canada (NSERC CRSNG). D.Y.S. was supported by a fellowship from École des Neuroscience de Paris (ENP), L.R. received a PhD fellowship from the Ministère de l'enseignement supérieur et de la recherche and from the Fondation pour la Recherche Médicale (FRM, FDT20140930909).

\section{AUTHORS CONTRIBUTION}

S.J., S.E.M. and S.D. conceived and designed the study. L.R., D.Y.S., A.H., O.P. and S.D. acquired, analyzed and interpreted data. D.Y.S., S.J. and S.D. wrote the paper. S.E.M. revised critically the article.

\section{CONFLICTS OF INTEREST}

The authors have no conflicts of interest to report.

\section{ORCID}

Stéphanie Daumas (D) https://orcid.org/0000-0001-7048-7617

\section{REFERENCES}

1. Purves D, Augustine GJ, Fitzpatrick D, et al. Neuroscience. Sunderland, Massachusetts: Sinauer Associates, Inc.; 2004.
2. El Mestikawy S, Wallen-Mackenzie A, Fortin GM, Descarries L, Trudeau LE. From glutamate co-release to vesicular synergy: vesicular glutamate transporters. Nat Rev Neurosci. 2011;12:204-216.

3. Fremeau RT Jr, Troyer MD, Pahner I, et al. The expression of vesicular glutamate transporters defines two classes of excitatory synapse. Neuron. 2001;31:247-260.

4. Herzog E, Bellenchi GC, Gras C, et al. The existence of a second vesicular glutamate transporter specifies subpopulations of glutamatergic neurons. J Neurosci. 2001;21:RC181.

5. Gras C, Herzog E, Bellenchi GC, et al. A third vesicular glutamate transporter expressed by cholinergic and serotoninergic neurons. J Neurosci. 2002;22:5442-5451.

6. Somogyi J, Baude A, Omori Y, et al. GABAergic basket cells expressing cholecystokinin contain vesicular glutamate transporter type 3 (VGLUT3) in their synaptic terminals in hippocampus and isocortex of the rat. Eur J Neurosci. 2004;19:552-569.

7. Fasano C, Rocchetti J, Pietrajtis K, et al. Regulation of the hippocampal network by VGLUT3-positive CCK-GABAergic basket cells. Front Cell Neurosci. 2017;11:140.

8. Gras C, Amilhon B, Lepicard EM, et al. The vesicular glutamate transporter VGLUT3 synergizes striatal acetylcholine tone. Nat Neurosci. 2008;11:292-300

9. Amilhon B, Lepicard E, Renoir T, et al. VGLUT3 (vesicular glutamate transporter type 3) contribution to the regulation of serotonergic transmission and anxiety. J Neurosci. 2010;30:2198-2210.

10. Sengupta A, Bocchio M, Bannerman DM, Sharp T, Capogna M. Control of amygdala circuits by $5-\mathrm{HT}$ neurons via $5-\mathrm{HT}$ and glutamate cotransmission. J Neurosci. 2017;37:1785-1796.

11. Sakae DY, Marti F, Lecca S, et al. The absence of VGLUT3 predisposes to cocaine abuse by increasing dopamine and glutamate signaling in the nucleus accumbens. Mol Psychiatry. 2015;20:1448-1459.

12. Crusio WE. Gene-targeting studies: new methods, old problems. Trends Neurosci. 1996;19:186-187. discussion 188-189.

13. Gerlai R. Gene-targeting studies of mammalian behavior: is it the mutation or the background genotype? Trends Neurosci. 1996;19: 177-181.

14. Frankel WN. Mouse strain backgrounds: more than black and white. Neuron. 1998;20:183.

15. Crawley JN. Behavioral phenotyping of transgenic and knockout mice: experimental design and evaluation of general health, sensory functions, motor abilities and specific behavioral tests. Brain Res. 1999; 835:18-26.

16. Bolivar V, Cook M, Flaherty L. List of transgenic and knockout mice: behavioral profiles. Mamm Genome. 2000;11:260-274.

17. Farley S, Dumas S, El Mestikawy S, Giros B. Increased expression of the vesicular glutamate transporter-1 (VGLUT1) in the prefrontal cortex correlates with differential vulnerability to chronic stress in various mouse strains: effects of fluoxetine and MK-801. Neuropharmacology. 2012;62:503-517.

18. Lassalle JM, Halley H, Daumas S, Verret L, Frances B. Effects of the genetic background on cognitive performances of TG2576 mice. Behav Brain Res. 2008;191:104-110.

19. Tarantino LM, Gould TJ, Druhan JP, Bucan M. Behavior and mutagenesis screens: the importance of baseline analysis of inbred strains. Mamm Genome. 2000;11:555-564.

20. Clement $Y$, Le Guisquet AM, Venault P, Chapouthier G, Belzung C. Pharmacological alterations of anxious behaviour in mice depending on both strain and the behavioural situation. PloS One. 2009;4:e7745.

21. Gill KJ, Boyle AE. Genetic influences on drug-induced psychomotor activation in mice. Genes Brain Behav. 2008;7:859-868.

22. Rodgers RJ, Davies B, Shore R. Absence of anxiolytic response to chlordiazepoxide in two common background strains exposed to the elevated plus-maze: importance and implications of behavioural baseline. Genes Brain Behav. 2002;1:242-251.

23. He M, Shippenberg TS. Strain differences in basal and cocaine-evoked dopamine dynamics in mouse striatum. J Pharmacol Exp Ther. 2000; 293:121-127.

24. Mathis C, Neumann PE, Gershenfeld H, Paul SM, Crawley JN. Genetic analysis of anxiety-related behaviors and responses to benzodiazepine-related drugs in AXB and BXA recombinant inbred mouse strains. Behav Genet. 1995;25:557-568. 
25. Deroche V, Caine SB, Heyser CJ, Polis I, Koob GF, Gold LH. Differences in the liability to self-administer intravenous cocaine between C57BL/6 x SJL and BALB/cByJ mice. Pharmacol Biochem Behav. 1997; 57:429-440.

26. Paxinos G, Franklin KBJ. The Mouse Brain in Stereotaxic Coordinates. 2nd ed. San Diego, California: Academic Press; 2001.

27. Takahashi M, Matsuda F, Margetic N, Lathrop M. Automated identification of single nucleotide polymorphisms from sequencing data. J Bioinform Comput Biol. 2003;1:253-265.

28. Agarwal V, Bell GW, Nam JW, Bartel DP. Predicting effective microRNA target sites in mammalian mRNAs. Elife. 2015;4:e05005.

29. Marinescu VD, Kohane IS, Riva A. MAPPER: a search engine for the computational identification of putative transcription factor binding sites in multiple genomes. BMC Bioinformatics. 2005;6:79.

30. Crabbe JC, Wahlsten D, Dudek BC. Genetics of mouse behavior: interactions with laboratory environment. Science. 1999;284:16701672.

31. Miner LL. Cocaine reward and locomotor activity in C57BL/6J and 129/SvJ inbred mice and their F1 cross. Pharmacol Biochem Behav. 1997;58:25-30.

32. Thomsen M, Caine SB. Psychomotor stimulant effects of cocaine in rats and 15 mouse strains. Exp Clin Psychopharmacol. 2011;19: 321-341.

33. Zhang Y, Mantsch JR, Schlussman SD, Ho A, Kreek MJ. Conditioned place preference after single doses or "binge" cocaine in C57BL/6 and 129/J mice. Pharmacol Biochem Behav. 2002;73:655-662.

34. Eisener-Dorman AF, Grabowski-Boase L, Tarantino LM. Cocaine locomotor activation, sensitization and place preference in six inbred strains of mice. Behav Brain Funct. 2011;7:29.

35. Karasinska JM, George SR, Cheng R, O'Dowd BF. Deletion of dopamine D1 and D3 receptors differentially affects spontaneous behaviour and cocaine-induced locomotor activity, reward and CREB phosphorylation. Eur J Neurosci. 2005;22:1741-1750.

36. Morice E, Denis C, Giros B, Nosten-Bertrand M. Phenotypic expression of the targeted null-mutation in the dopamine transporter gene varies as a function of the genetic background. Eur J Neurosci. 2004; 20:120-126.

37. Mead AN, Rocha BA, Donovan DM, Katz JL. Intravenous cocaine induced-activity and behavioural sensitization in norepinephrine-, but not dopamine-transporter knockout mice. Eur J Neurosci. 2002;16: 514-520.

38. Thomsen M, Han DD, Gu HH, Caine SB. Lack of cocaine selfadministration in mice expressing a cocaine-insensitive dopamine transporter. J Pharmacol Exp Ther. 2009;331:204-211.

39. Lad HV, Liu L, Paya-Cano JL, et al. Behavioural battery testing: evaluation and behavioural outcomes in 8 inbred mouse strains. Physiol Behav. 2010;99:301-316.

40. Keum S, Park J, Kim A, et al. Variability in empathic fear response among 11 inbred strains of mice. Genes Brain Behav. 2016;15: 231-242.

41. Rogers DC, Jones DN, Nelson PR, et al. Use of SHIRPA and discriminant analysis to characterise marked differences in the behavioural phenotype of six inbred mouse strains. Behav Brain Res. 1999;105: 207-217.

42. Fraser LM, Brown RE, Hussin A, et al. Measuring anxiety- and locomotion-related behaviours in mice: a new way of using old tests. Psychopharmacology (Berl). 2010;211:99-112.

43. Balazsfi D, Fodor A, Torok B, et al. Enhanced innate fear and altered stress axis regulation in VGluT3 knockout mice. Stress. 2018;21: 151-161.

44. Horvath HR, Fazekas CL, Balazsfi D, Jain SK, Haller J, Zelena D. Contribution of vesicular glutamate transporters to stress response and related psychopathologies: studies in VGluT3 knockout mice. Cell Mol Neurobiol. 2018;38:37-52.

\section{SUPPORTING INFORMATION}

Additional supporting information may be found online in the Supporting Information section at the end of the article. 